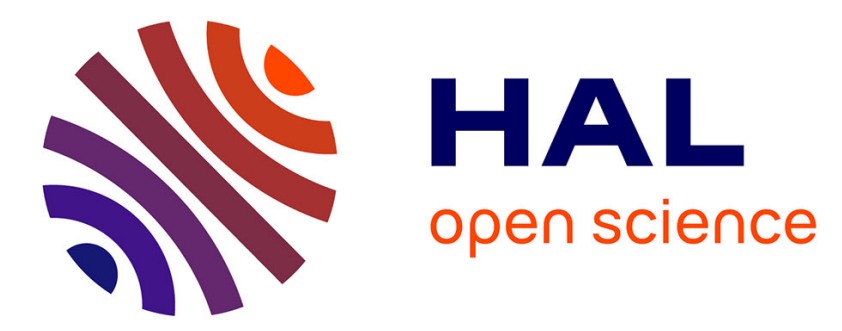

\title{
Blood pressure measurements on a bare arm, over a sleeve or below a rolled-up sleeve: a systematic review and meta-analysis
}

David Seguret, Danaé Gamelon, Caroline Dourmap, Olivier Steichen

\section{- To cite this version:}

David Seguret, Danaé Gamelon, Caroline Dourmap, Olivier Steichen. Blood pressure measurements on a bare arm, over a sleeve or below a rolled-up sleeve: a systematic review and meta-analysis. Journal of Hypertension, 2020, 38 (9), pp.1650-1658. 10.1097/HJH.0000000000002460 . hal-02978538

\section{HAL Id: hal-02978538 \\ https: / hal.sorbonne-universite.fr/hal-02978538}

Submitted on 26 Oct 2020

HAL is a multi-disciplinary open access archive for the deposit and dissemination of scientific research documents, whether they are published or not. The documents may come from teaching and research institutions in France or abroad, or from public or private research centers.
L'archive ouverte pluridisciplinaire HAL, est destinée au dépôt et à la diffusion de documents scientifiques de niveau recherche, publiés ou non, émanant des établissements d'enseignement et de recherche français ou étrangers, des laboratoires publics ou privés. 
We are grateful for the time and commitment the reviewers have devoted to our work. We have carefully considered and addressed their questions, comments and suggestions. Thanks to the reviewers input, we think that the revised manuscript is more informative and clear.

Detailed answers to each point raised by the reviewers are provided below in italic type. Modifications are apparent in red type in our reply and in the revised manuscript.

\section{Editorial request:}

As the Journal of Hypertension is the official journal of ESH, the Editorial Board would kindly like to invite you to replace this reference with the identical version of the ESC-ESH Guidelines 2018 published in the Journal of Hypertension.

This has been changed.

\section{Reviewer \#1}

Reviewer \#1: The authors may want to relate to a recent study that find that even several layers of clothing do not have a major effect on measured BP, Woloszin P, Wilderness Env Med 2019;30:227-35

Thank you to the reviewer for pointing out that new evidence has been published since the completion of our review. We therefore relaunched the queries in the bibliographic databases to update the review.

The study indicated by the reviewer was the only new relevant one identified. We have changed the review flowchart, the tables and meta-analyses to include the description and results of this study. The preferred random meta-analysis methods changed with the new version of our statistical software (from der Simonian Laird in Stata 15 to restricted maximum likelihood in Stata 16), explaining small changes in the 95\% confidence intervals of several pooled estimates.

This study highlights that BP measurement over a thick sleeve can be unbiased but not precise enough for clinical purposes. We have therefore analysed the within-subject variability of BP measurements performed on a bare arm and over a sleeve. These analyses are described in the methods and their results are reported in a dedicated section.

End of the Methods:

"The results of one study where BP measurements over a sleeve or on a bare arm differed markedly in each individual participants although the average difference across the group was close to zero [Woloszyn 2019]. Indeed, the accuracy of BP measurements over a sleeve breaks down to possible bias (systematic error) and possible imprecision (random error). Bias is estimated by the mean BP difference between measurements over a sleeve and on a bare arm and was investigated by the meta-analyses. Imprecision is estimated by the standard deviation of the BP difference between measurements over a sleeve and on a bare arm. We therefore performed post hoc comparisons of the standard deviations:

- of the BP difference between measurements over a sleeve and on a bare arm with the BP difference between repeated measurements on a bare arm;

- of the BP difference between measurements over different sleeves and on a bare arm."

End of the Results and Supplementary Table S6:

"Supplementary Table S6 reports the comparisons of within-subject variability of SBP measured on a bare arm and on a sleeve or on different sleeves. The within-subject variability between measurement on a bare arm and over a (thin) sleeve was similar to the within-subject variability between two successive measurements on a bare arm in the single study with available data [Ma 2008]. By contrast, several studies found a higher withinsubject variability between measurements over the thickest sleeve (or the sleeve with more layers) and on a bare arm than between measurements over the thinnest sleeve (or the sleeve with less layers) and on a bare arm (Supplementary Table S6)." 
Their implication is highlithed in the Discussion (Implications):

"Moreover, the within-subject variability between a BP measurement over a thin sleeve and on a bare arm was similar to the within-subject variability between two consecutive measurements on a bare arm. BP

measurement over a thin sleeve does therefore not increase the risk of random misclassification compared to measurement on a bare arm. By contrast, BP measurements over a thick sleeve increase the risk of random misclassification compared to measurement on a bare arm and should therefore be avoided when possible, even though they are on average unbiased."

\section{Reviewer \#2}

Reviewer \#2: The effect of adiposity on the BP differences is of interest. To better understand the effect of arm size on the BP measurement, is arm circumference available among the subjects' characteristics?

It is true that the effect of adiposity on BP measurement is mediated by arm circumference. However, only 3/13 studies only report mean arm circumference. We have added a column in the Table S3 (Participant characteristics) to report arm size when available.

Body-mass index (BMI) was more often available (9/13 studies) and it is known to correlate well with arm size [see for example PLoS One 2016;11:e0160480 // Saudi J Anaesth 2016;10:182-6]. We therefore used BMI in our analyses.

We have added a sentence to address this issue in the Discussion (Future work):

"Since our review suggests an association between mean BP differences across measurement conditions and adiposity, future studies will need to assess precisely the influence of this factor at the individual participant level. To this end, arm circumference should be analysed because it possibly mediates the interaction between $\mathrm{BMI}$ and the effect on the sleeve on BP measurements."

Reviewer \#2: Page 4, bottom. The term patient should not be used as not all subjects were hypertensive.

This is right, thank you. We have changed "patients" to "participants" where appropriate.

Reviewer \#2: A third reviewer resolved disagreements. How often was this required?

The number of references selected on titles and abstracts by the two reviewers was low (15 and 16 respectively, including 13 in common) and all the 18 papers selected by at least one of them was read in full text. Their agreement on full text papers was perfect. An intervention of the third reviewer was therefore never needed.

We changed the phrasing in the Methods (Study selection):

"An independent reviewer (OS) assessed and resolved disagreements when needed."

Reviewer \#2: In the 4 studies performed with the auscultatory method, where was the stethoscope placed?

This is a good point, the stethoscope could be placed on the skin even when the cuff is on the sleeve. The information was available in one report only [Liebl 2004]: the stethoscope was placed over the sleeve as well as the cuff.

The following sentence has been added to the Results (Study charactéristics, Methods of BP measurement): "Among studies investigating auscultatory measurements, a single one reported that the stethoscope was placed over the sleeve when the cuff was [19]."

Reviewer \#2: Figure 3. The results are clearly influenced by the 2 studies by Ozone et al. that were performed in $75 \mathrm{y}$ old and $\mathbf{8 7} \mathrm{y}$ old people. These are the only studies performed in elderly people and the results are at 
variance with those of all other studies. Additional data should be provided after excluding those 2 studies. A comment on the possible effect of age on the effect of sleeve on BP measurement should be included.

This is perfectly true. The participants in the 2 studies by Ozone et al differ by their age and their BMI, and they report the highest diferences between measurements over a sleeve and on a bare arm. They could therefore induce a leverage effect on the meta-regressions on age and on BMI.

We therefore ran again the meta-regression models after excluding these studies. The effect of age was no longer significant across the remaining studies, whereas the effect of BMI remained similar and significant. The lower BMI of participants is therefore a more plausible explaination of the findings of the two Japanese studies than their older age.

We have added the meta-regression on age and the results of meta-regressions on BMI and age after exclusion of the 2 Japanese studies in the Results:

"Meta-regression performed from the 8 studies providing the required data showed an negative association between mean BMI and mean SBP difference, with a regression coefficient of -0.44 ( $95 \% \mathrm{Cl}:-0.68$ to -0.21 , $p=0.01$, Supplementary Figure $S 5$ ). The association remained of similar magnitude (regression coefficient -0.30 ) and statistically significant $(p=0.02$ ) when the two studies with markedly lower mean BMI were excluded $[17,28]$. Meta-regression performed from the 12 studies showed a positive association between mean age and mean SBP difference, with a regression coefficient of $0.04(95 \% \mathrm{Cl}:-0.001$ to $-0.08, p=0.04$, Supplementary Figure S6). However, the association vanished (correlation coefficient $-0.01, p=0.64)$ ) when the two studies with markedly older participants were excluded $[17,28] . "$

Reviewer \#2: A study by Ozone is reported sometimes as Ozone 2017 and sometimes as Ozone 2018, but there is no Ozone 2017 among the references. Check throughout text, tables and figures.

We have changed this study label to "Ozone 2018" everywhere.

Reviewer \#2: A comment on the results obtained with the oscillometric vs auscultatory measurement should be included in the Discussion.

Thank you for pointing the lack of discussion of these results. A sentence has been added to the Discussion (Limitations):

"Although no statistically significant differences were found between auscultatory and oscillometric measurements, reported data lacked details on the auscultatory technique, especially regarding the position of the stethoscope over or under the sleeve."

Reviewer \#2: Ref 3 for AHA recommendations should be updated (see Hypertension 2019)

This has been done.

Reviewer \#2: Ref 4 and 5. The source of information should be displayed.

The websites where the instruction manuals can be retrieved have been added.

Reviewer \#2: The J Hypertens. 2005 Apr;23(4):697-701 reference should be included among the ESH recommendations.

As requested by the editor, we have used the reference to the latest version of the ESH recommendations [J Hypertens 2018;36:1953-2041]. 


\section{Abbreviations definition list}

BP: blood pressure

SBP: systolic blood pressure

DBP: diastolic blood pressure

$\mathrm{Cl}$ : confidence interval

PRISMA: preferred reporting items for systematic reviews and meta-analyses

PROSPERO: international prospective register of systematic reviews

QUADAS-2: quality assessment tool for diagnostic accuracy studies, second version 


\section{CONDENSED ABSTRACT}

We report a systematic review of 13 articles comparing BP values measured on a bare arm, over a sleeve or below a rolled-up sleeve. Most studies did not find statistically significant differences between measurements. Meta-analysis showed a non-significant $0.59 \mathrm{mmHg}$ [95\% Cl -0.11 to 1.30; $p=0.10$ ] overestimation of systolic BP (SBP) measured over a sleeve when the thinnest sleeve was considered for studies that investigated various thicknesses, a non-significant $1.10 \mathrm{mmHg}$ [95\% $\mathrm{Cl}-0.21$ to $2.40 ; p=0.10$ ] overestimation of SBP when the thickest sleeve was considered, and a non-significant $2.76 \mathrm{mmHg}[95 \% \mathrm{Cl}-0.96$ to $6.47 ; \mathrm{p}=$ 0.15] overestimation of SBP measured below a rolled-up sleeve. 
Blood pressure measurements on a bare arm, over a sleeve or below a rolled-up sleeve: a systematic review and meta-analysis

\section{Short title}

Effect of the sleeve on BP measurements

\section{Authors}

David SEGURET a , Danaé GAMELON a , Caroline DOURMAP ${ }^{\text {b }}$, Olivier STEICHEN a,c

a Assistance Publique - Hôpitaux de Paris, Sorbonne Université, Hôpital Tenon, Department of Internal Medicine, Paris, France

${ }^{\mathrm{b}} \mathrm{CHU}$ de Rennes, Department of Cardiology and Vascular Medicine, Rennes, France

c Inserm UMRS 1142, Sorbonne Université, Université Paris 13, LIMICS, Paris, France

\section{Prior presentations}

12/14/2018: Oral communication at the French Society of Hypertension annual meeting in Paris, France

6/22/2019: Poster presented at the European Society of Hypertension annual meeting in Milan, Italy

\section{Support and funding}

None

\section{Conflicts of interest}

None reported

Word count for the main text (including references): 4304

\section{Corresponding author}

Professeur Olivier Steichen

Service de médecine interne

Hôpital Tenon

4 rue de la Chine, 75020 Paris, France

Tel: +33156017831

Fax: +33156017146

olivier.steichen@aphp.fr 


\section{Tables}

Table 1. Methods of blood pressure measurement

Table 2. Risk of bias within studies

Table 3. Results of individual studies

\section{Figures}

Figure 1. Flow diagram of studies identified and included in the review

Figure 2. Forest plot of mean SBP differences considering the thinnest sleeves

Figure 3. Forest plot of mean SBP differences considering the thickest sleeves

\section{Supplemental content}

Figure S1. Forest plot of mean SBP differences measured below a rolled-up sleeve

Figure S2. Funnel plot for studies considering the thinnest sleeve

Figure S3. Funnel plot for studies considering the thickest sleeve

Figure S4. Forest plot of mean SBP differences for auscultatory and oscillometric measurements

Figure S5. Linear meta-regression plot of mean SBP difference against mean BMI

Figure S6. Linear meta-regression plot of mean SBP difference against mean age

Table S1. Items assessed in the adaptation of the QUADAS-2 tool

Table S2. Setting and selection criteria

Table S3. Participant characteristics

Table S4. Statistical methods reported in individual studies

Table S5. Meta-regression analyses between selected characteristics and mean SBP difference

Table S6. Within-subject variability of SBP measured on a bare arm and on a sleeve or on different sleeves

Table S7. PRISMA checklist 


\section{ABSTRACT}

\section{Objective}

Several guidelines call for blood pressure (BP) measurement on a bare arm, which is not always easy. This systematic review aims to synthesize existing evidence concerning the effect of a sleeve on BP measurement.

\section{Methods}

Pubmed and Embase were searched for cross-sectional studies comparing BP values measured on a bare arm, over a sleeve or below a rolled-up sleeve. A meta-analysis was conducted on available data.

\section{Results}

Thirteen articles were selected from 720 references. All studies reported office BP values, 12 compared measurements on a bare arm and on a sleeve, and 4 also performed measurements below a rolled-up sleeve, with heterogeneous sleeve types and thicknesses. Most studies had a high risk of bias.

Three studies showed a small overestimation of BP measured over a sleeve, but the remaining 10 studies did not find statistically significant differences between measurements. Meta-analysis showed a non-significant $0.59 \mathrm{mmHg}[95 \% \mathrm{Cl}-0.11$ to $1.30 ; \mathrm{p}$ $=0.10]$ overestimation of systolic BP (SBP) measured over a sleeve when the thinnest sleeve was considered for studies that investigated various thicknesses, a non-significant 1.10 $\mathrm{mmHg}[95 \% \mathrm{Cl}-0.21$ to $2.40 ; p=0.10$ ] overestimation of SBP when the thickest sleeve was considered, and a non-significant $2.76 \mathrm{mmHg}$ [95\% $\mathrm{Cl}-0.96$ to $6.47 ; \mathrm{p}=0.15$ ] overestimation of SBP measured below a rolled-up sleeve. 


\section{Conclusions}

Measuring BP over a thick sleeve in the office may result in a small overestimation of recorded values but measuring over a thin sleeve does not appear to have a significant impact and, in any case, should be preferred to rolling it up.

\section{CONDENSED ABSTRACT}

We report a systematic review of 13 articles comparing BP values measured on a bare arm, over a sleeve or below a rolled-up sleeve. Most studies did not find statistically significant differences between measurements. Meta-analysis showed a non-significant $0.59 \mathrm{mmHg}$ [95\% Cl -0.11 to 1.30; $p=0.10$ ] overestimation of systolic BP (SBP) measured over a sleeve when the thinnest sleeve was considered for studies that investigated various thicknesses, a non-significant $1.10 \mathrm{mmHg}$ [95\% $\mathrm{Cl}-0.21$ to $2.40 ; p=0.10$ ] overestimation of SBP when the thickest sleeve was considered, and a non-significant $2.76 \mathrm{mmHg}[95 \% \mathrm{Cl}-0.96$ to $6.47 ; \mathrm{p}=$ 0.15] overestimation of SBP measured below a rolled-up sleeve.

\section{KEY WORDS}

Blood Pressure Determination

Hypertension

Clothing 


\section{INTRODUCTION}

Blood pressure (BP) is commonly measured in office-based and inpatient settings. Many factors can interfere with the readings, dependent on the patient or the measurement protocol [1]. Among these factors, the influence of wearing a sleeve under the cuff is still controversial. Nonetheless, healthcare practitioners often carry out the measurement over a sleeve, or on a bare arm below a rolled-up sleeve [2].

Measurement on a sleeve could theoretically alter the transmission of cuff pressure and overestimate the BP. There is also a risk of reduced Korotkoff sounds in the case of auscultatory measurements with the stethoscope over a sleeve, or poor pulse signal that may decrease the accuracy of oscillometric devices. Rolling up the sleeve could lead to a tourniquet effect and thus underestimate BP values measured with the cuff placed below [3]. Some instruction manuals of automatic BP monitors recommend placing the cuff directly against the skin, as clothing may cause a faint pulse and results in errors [4]. Other manuals advise not to place the cuff over thick sleeves [5]. Some guidelines advocate measurement on a bare arm [3,6-9], but others do not provide an explicit recommendation on this point [10-13].

Several diagnostic studies have focused on the comparison of BP values with or without a sleeve underneath the cuff, but no comprehensive synthesis exists to date. A review of available evidence is therefore needed to inform clinical practice. The goal of this study is to assess whether measuring BP over a sleeve or on an arm with a rolled-up sleeve change the readings compared to measuring $\mathrm{BP}$ on a bare arm. 


\section{METHODS}

The study protocol was registered with PROSPERO (International prospective register of systematic reviews, ID CRD42017054593). This report complies with the PRISMA statement [14].

\section{Eligibility criteria}

We included cross-sectional studies comparing BP readings on a bare arm with readings over a sleeve and/or under a rolled-up sleeve within the same subject during the same encounter or between two groups of participants.

\section{Information sources and search strategy}

Studies were identified in Pubmed and Embase from inception to February 2020 the $5^{\text {th }}$, without any language or time restriction. We designed a search equation based on the following pattern: (bare OR sleeve OR sleeved OR clothing OR clothes) AND ("blood pressure measurement" OR "blood pressure measurements" OR "blood pressure determination" OR hypertension) NOT (bariatric OR gastrectomy OR gastroplasty OR stent OR stents). Terms related to sleeve gastrectomy and bare-metal stents were excluded to avoid noise in our results.

\section{Study selection}

Eligibility assessment was performed independently by two reviewers (DS, DG) with the help of a reference management software (JabRef version 3.8.1). Obviously irrelevant references were first rejected on title and abstract. The final selection was performed after reading the 
full text of remaining references. An independent reviewer (OS) assessed and resolved disagreements when needed.

We checked references cited in included articles to identify relevant studies not initially screened by our search equation. We also used Web of Science to retrieve additional references among those citing the selected articles.

\section{Data extraction}

Two reviewers (DS, DG) independently extracted data from each included article. An independent reviewer (OS) resolved disagreements when needed. We systematically tried to contact authors to retrieve additional data when the provided outcome measurements were insufficient.

The information we collected across all selected studies consisted of:

(1) Selection process and participant characteristics: study setting, source population, number of participants evaluated and included, methods of sample selection, mean age, sex, mean body mass index (BMI), arm circumference, and relevant medical history.

(2) Detailed methods of BP measurement: type of device (with the position of stethoscope for the auscultatory method), number of measures for each cuff placement, measurement order randomization, operator blinding techniques, sleeve type and thickness, overall respect of good practices.

(3) Data flow description: presence of a participant flowchart, number, type and handling of missing data, number of protocol violations.

(4) Statistical methods: description of the sample size prerequisites, of the main comparison tests used and of correlation or agreement tests. 
(5) Results of each study: mean difference between the systolic/diastolic BP measured in various conditions (with sleeve, on bare arm, with a rolled-up sleeve), with the associated confidence interval $(\mathrm{Cl})$ and/or standard deviation.

\section{Risk of bias in individual studies}

To assess the quality of eligible studies, we used an adaptation of the QUADAS-2 tool for diagnostic accuracy studies [15]. Our evaluation was not blinded and focused on participant selection, BP measurement, data flow, and statistical methods (see Supplementary Table S1).

\section{Data analysis}

We performed a meta-analysis by computing mean differences of BP measured between over a sleeve or below a rolled-up sleeve and on a bare arm, using a study-level randomeffects model. Studies providing no usable outcomes (e.g. no mean differences or mean differences impossible to infer from provided data) were not used for the meta-analysis. When not plainly stated but presented on a box plot, median and quartiles were measured on the figure with PDF-XChange Viewer 2.5 (Tracker Software, Henfield, UK). We assessed between-study heterogeneity in effect measures using both the Cochrane $\mathrm{Chi}^{2}$ test and the $\mathrm{I}^{2}$ statistic. We considered an $\mathrm{I}^{2}$ value greater than $50 \%$ indicative of substantial heterogeneity. The possibility of publication bias was assessed both visually on a funnel plot, and formally with Egger's linear regression test. We planned 5 subgroup analyses: (1) for people with or without hypertension; (2) for obese or normal weight persons; (3) for ambulatory or office measurement; (4) for automated or manual BP readings; (5) for thin or thick sleeves. 
The results of one study where BP measurements over a sleeve or on a bare arm differed markedly in each individual participant although the average difference across the group was close to zero [16]. Indeed, the accuracy of BP measurements over a sleeve breaks down to possible bias (systematic error) and possible imprecision (random error). Bias is estimated by the mean BP difference between measurements over a sleeve and on a bare arm and was investigated by the meta-analyses. Imprecision is estimated by the standard deviation of the BP difference between measurements over a sleeve and on a bare arm. We therefore performed post hoc comparisons of the standard deviations:

- of the BP difference between measurements over a sleeve and on a bare arm with the BP difference between repeated measurements on a bare arm; - of the BP difference between measurements over different sleeves and on a bare arm. All analyses were performed using Stata 16.1 (StataCorp, College Station, TX). 


\section{RESULTS}

Among 720 references screened after identification through Pubmed, Embase and Web of Science, 707 were excluded on title and/or abstract because unrelated to BP measurement and cuff placement or reporting no original data (Figure 1). Thirteen studies were included in the qualitative analysis. One study did not report the required statistical data for the meta-analysis.

\section{Study characteristics}

Setting and selection criteria (Supplementary Table S2)

Dates of publication ranged from 1993 to 2019. Measurements were always performed in office-based or inpatient settings and two studies included only hospitalized patients $[17,18]$. Source populations were either restricted to a specific group, not restricted, or unspecified (one study [19]). Exclusion criteria were specified in 10 articles and consisted mostly of factors known to alter the BP values measured with electronic devices (such as arrhythmia), and/or factors that could bias measurement (such as caffeine or alcohol consumption before enrolment).

Participant characteristics (Supplementary Table S3)

Participant mean age ranged from 32.3 to 87.2 years. The proportion of hypertensive patients ranged from 0 to $100 \%$. Baseline BP measurements on a bare arm were reported in 10 articles and were inferred from figures presented in 2 articles $[17,20]$.

Methods of BP measurement (Table 1)

Twelve studies compared measurements on a bare arm and on a sleeve, among which 4 also compared measurements on a bare arm and below a rolled-up sleeve. One study only 
compared measurements on a sleeve and below a rolled-up sleeve [21]. In most cases, measurements were repeated 3 times for each cuff placement. Type and thickness of sleeves varied greatly. Mean thicknesses ranged from $<1 \mathrm{~mm}$ to $17 \mathrm{~mm}$, when reported. Nine studies investigated oscillometric measurements only, 2 studies auscultatory measurements only, and 2 studies investigated both. Among studies investigating auscultatory measurements, a single one reported that the stethoscope was placed over the sleeve when the cuff was [20].

\section{Risk of bias within studies (Table 2)}

Inclusion criteria were unspecified in 3 studies [22-24]. In most articles, the sample selection process was either not specified or unclear, especially regarding the enrollment sequence being consecutive or not. Only 2 studies reported a flowchart for participant selection and group allocation (bare or sleeved-arm) [21,25]. Good measurement practices were ascertained in 10 studies. Three studies reported effective blinding of observers $[17,20,26]$. Data flowchart and methods for missing data handling were not found in any article. Methods for statistical analysis were reported in all articles (Supplementary Table S4). Appropriate power and decision tests were specified in most studies. Agreement was appropriately analyzed in 6 studies (Bland-Altman plots in all cases) [27].

\section{Results of individual studies (Table 3)}

Three studies showed a small but statistically significant overestimation of systolic BP (SBP) and diastolic BP (DBP) measured over a sleeve compared to the bare arm $[18,28,29]$. The remaining 9 studies did not find statistically significant differences between measurements over a sleeve or on a bare arm. Two studies comparing BP measurements under a rolled-up sleeve or on the bare arm found a significant overestimation of SBP and DBP $[18,29]$ 
whereas the two other did not $[19,23]$. The study comparing measurements over a sleeve and under a rolled-up sleeve did not find a significant difference [21].

\section{Syntheses of results}

The combined effect computed using a random-effects model was a non-significant 0.59 $\mathrm{mmHg}$ overestimation of SBP measured over a sleeve $(95 \% \mathrm{Cl}-0.11$ to $1.30, \mathrm{p}=0.10$, Figure 2), considering oscillometric measurements when the two techniques were used, and the thinnest sleeves for studies using different sleeve thicknesses (single thin layer for eight studies $[17,18,21,23,24,26,28,29])$.

When considering the thickest sleeves for each study (single thin layer for five studies $[20,23,24,26,29])$, we found a non-significant $1.10 \mathrm{mmHg}$ overestimation of SBP measured over a sleeve $(95 \% \mathrm{Cl}-0.21$ to $2.10, \mathrm{p}=0.10$, Figure 3$)$.

Meta-analysis of the four studies providing the needed data found a statistically nonsignificant $2.76 \mathrm{mmHg}$ overestimation of SBP measured below a rolled-up sleeve $(95 \% \mathrm{Cl}$ 0.96 to $6.47, p=0.15$, Supplementary Figure S1).

\section{Risk of bias across studies}

A funnel plot based on the meta-analysis focused on the thinnest sleeves shows a symmetrical distribution of mean SBP differences around the summary mean difference (Supplementary Figure S2). Egger's test confirmed the lack of significant asymmetry ( $p=$ $0.64)$.

When considering the thickest sleeves, the funnel plot shows 2 studies reporting a mean SBP difference markedly greater than the summary mean difference $[18,29]$, yet without a significant asymmetry according to Egger's test ( $p=0.69$, Supplementary Figure S3). 


\section{Additional analyses}

Computed meta-analyses reported significant between-study heterogeneity regarding SBP measurements on a bare arm compared to measurements over a sleeve $\left(I^{2}=71 \%\right.$ with the thinnest sleeves and $91 \%$ with the thickest) or below a rolled-up sleeve $\left(I^{2}=95 \%\right)$. Two studies stand out by showing a greater overestimation of BP measured on a sleeve $[18,29]$. Planned subgroup analyses and meta-regressions were performed, when the needed data was available, using results obtained with the oscillometric method and the thinnest sleeve when possible.

There was no statistically significant difference between summary mean SBP differences computed from the values obtained with auscultatory or oscillometric measurements $(p=$ 0.87, Supplementary Figure S4). Meta-regression performed from the 8 studies providing the required data showed a negative association between mean BMI and mean SBP difference, with a regression coefficient of -0.44 (95\% Cl: -0.68 to $-0.21, p=0.01$, Supplementary Figure S5). The association remained of similar magnitude (regression coefficient -0.30$)$ and statistically significant $(p=0.02)$ when the two studies with markedly lower mean BMI were excluded [18,29]. Meta-regression performed from the 12 studies showed a positive association between mean age and mean SBP difference, with a regression coefficient of 0.04 ( $95 \% \mathrm{Cl}:-0.001$ to $-0.08, \mathrm{p}=0.04$, Supplementary Figure $\mathrm{S} 6$ ). However, the association vanished (correlation coefficient $-0.01, p=0.64)$ ) when the two studies with markedly older participants were excluded $[18,29]$. Meta-regressions performed according to the proportion of hypertensive subjects and sex ratio did not show any significant association with the mean SBP difference (Supplementary Table S5). Supplementary Table S6 reports the comparisons of within-subject variability of SBP measured on a bare arm and on a sleeve or on different sleeves. The within-subject 
variability between measurements on a bare arm and over a (thin) sleeve was similar to the within-subject variability between two successive measurements on a bare arm in the single study with available data [25]. By contrast, several studies found a higher within-subject variability between measurements over the thickest sleeve (or the sleeve with more layers) and on a bare arm than between measurements over the thinnest sleeve (or the sleeve with the fewest layers) and on a bare arm (Supplementary Table S6). 


\section{DISCUSSION}

\section{Summary of evidence}

Most studies included in our review found no statistically significant difference between BP measured on a bare arm, over a sleeve or below a rolled-up sleeve. Overall, the combined effect of measuring over a sleeve was a non-significant $0.59 \mathrm{mmHg}$ overestimation of the SBP with a narrow confidence interval (upper bound of $1.30 \mathrm{mmHg}$ ) when considering the thinnest sleeve for each study, and a non-significant $1.10 \mathrm{mmHg}$ overestimation of the SBP with a wider confidence interval (upper bound of $2.40 \mathrm{mmHg}$ ) when considering the thickest sleeve. Meta-regression analyses showed a greater average overestimation of BP measured over a sleeve in studies with lower average BMI.

\section{Limitations}

The quality of included studies varied greatly, which may limit their interpretation. Using an adaptation of the criteria provided by the QUADAS- 2 tool, we found that most studies had a significant risk of bias, particularly with respect to enrolment process, allocation of measurements and blinding of operators. However, conditions for measuring BP were mostly well documented and in line with good measurement practices that reduce intraindividual variability and improve the power to reveal a difference between measurement conditions [1].

Participant characteristics varied greatly when they were reported. In most cases, presence of arrhythmia was part of the exclusion criteria (due to the risk of error related to the oscillometric measurement method), which could limit the applicability of the results to affected patients. Subjects with a BMI greater than $25 \mathrm{~kg} / \mathrm{m}^{2}$ were overrepresented and the 
impact of the sleeve seems less in this group, which may have reduced its overall estimation.

The type of fabric and the thickness of the sleeves used for the measurements varied across studies. Some investigators used standardized clothes with controlled sleeve thicknesses, while others kept participants' clothing. This latter choice could be more representative of actual clinical practice.

Although no statistically significant differences were found between auscultatory and oscillometric measurements, reported data lacked details on the auscultatory technique, especially regarding the position of the stethoscope over or under the sleeve. All studies reported clinical BP measurements and none reported ambulatory or home measurements, which prevents us from drawing direct conclusions about the effect of the sleeve under these conditions.

The review process also has several limitations. Some studies could have been missed because our search was limited to large electronic databases and may have omitted more confidential publications, especially those published in languages other than English. We attempted to mitigate this risk by systematically reviewing all references cited in included articles and those citing them after publication. The QUADAS-2 tool for risk of bias assessment primarily targets diagnostic studies, whereas included studies are agreement analyses, for which this tool is imperfect [30]. The meta-analyses are limited by the number of available data, especially for the 4 studies assessing measurements performed below a rolled-up sleeve.

\section{Implications}


BP measurements with the cuff placed on a sleeve seem acceptable in clinical practice. The 95\% $\mathrm{Cl}$ upper bound of the summary estimate for SBP found after meta-analysis, which denotes the maximum bias induced by the sleeve, is $1.30 \mathrm{mmHg}$ with the thinnest ones and $2.40 \mathrm{mmHg}$ with the thickest.

The risk of a clinically significant systematic overestimation of SBP values measured on a thin sleeve is low with respect to the known variability of BP measurements in the same subject during the same encounter [1] or between different consultations [31], which is about $10 \mathrm{mmHg}$. The maximum bias is also lower than the measurement accuracy of modern automatic devices, which is generally $3 \mathrm{mmHg}[4,5]$ and lower than the $5 \mathrm{mmHg}$ threshold adopted by the Association for the Advancement of Medical Instrumentation to define an acceptable calibration of oscillometric devices [32]. This risk of systematic overestimation seems also small compared to other factors of BP measurement variability, such as crossed legs $(+2.5$ to $+14.9 \mathrm{mmHg}$ for SBP) or talking during the procedure $(+4$ to $+19 \mathrm{mmHg}$ ) [1]

Moreover, the within-subject variability between a BP measurement over a thin sleeve and on a bare arm was similar to the within-subject variability between two consecutive measurements on a bare arm. BP measurement over a thin sleeve does therefore not increase the risk of random misclassification compared to measurement on a bare arm. By contrast, BP measurements over a thick sleeve increase the risk of random misclassification compared to measurement on a bare arm and should therefore be avoided when possible, even though they are on average unbiased.

The $2.76 \mathrm{mmHg}$ overestimation of SBP measured below a rolled-up sleeve is not statistically significant, but the upper bound of the $95 \% \mathrm{Cl}$ is compatible with a clinically relevant difference $(6.47 \mathrm{mmHg})$. It is therefore preferable to measure BP over a thin sleeve rather 
than below a rolled-up sleeve, since overestimation of obtained values is possibly greater in the last situation.

The overestimation of BP measurements over a sleeve was larger in leaner participants. The sleeve might have been more wrinkled in these cases, leading to several interfaced layers between the arm and the cuff, thus increasing BP values through a poor transmission of the pulse or counterpressure.

\section{Future work}

Studies included in this review did not investigate the impact of clothing on ambulatory or home BP values. Extrapolation of our findings to these contexts is therefore uncertain. However, ambulatory BP monitoring is always conducted on a bare arm and home BP measurements are usually performed at times when undressing is easier. Measurements on a bare arm should therefore remain the preferred option.

Only a few of included studies had a low risk of bias, particularly with respect to participant selection and measurement methods. A study ensuring strict control of these biases could improve the strength of evidence. The protocol should comply to established guidelines for diagnostic accuracy studies, focusing on random allocation of measurements (or simultaneous measurements on both arms), and effective operator blinding [33]. Since our review suggests an association between mean BP differences across measurement conditions and adiposity, future studies will need to assess precisely the influence of this factor at the individual participant level. To this end, arm circumference should be analysed because it possibly mediates the interaction between $\mathrm{BMI}$ and the effect of the sleeve on $\mathrm{BP}$ measurements. 
The specific influence of the type of fabric, thickness of sleeve and number of layers above which measurements can be conducted remain uncertain. Studies providing comparative analyses of measures stratified or adjusted according to these characteristics could help clarify this issue.

\section{Conclusions}

BP measurement over a sleeve does not seem to have a major clinical impact, especially if the sleeve is less than $2 \mathrm{~mm}$ thick. The possible resulting overestimation of BP compared with measurements on a bare arm is less than the measurement error of modern oscillometric devices and the intra-individual short-term BP variability. When a thin shirt cannot be removed, measurement over the sleeve should be preferred to measurement below the rolled-up sleeve, which might be less reliable.

\section{ACKNOWLEDGMENTS}

We warmly thank Dr. Sachiko Ozone and Dr. Przemyslaw Woloszyn who kindly took the time to compute and provide results at the required format for meta-analyses. 


\section{REFERENCES}

1 Kallioinen N, Hill A, Horswill MS, Ward HE, Watson MO. Sources of inaccuracy in the measurement of adult patients' resting blood pressure in clinical settings: A systematic review. J Hypertens 2017; 35:421-441.

2 Rabbia F, Testa E, Rabbia S, Praticò S, Colasanto C, Montersino F, et al. Effectiveness of blood pressure educational and evaluation program for the improvement of measurement accuracy among nurses. High Blood Press Cardiovasc Prev 2013; 20:7780.

3 Muntner P, Shimbo D, Carey RM, Charleston JB, Gaillard T, Misra S, et al. Measurement of blood pressure in humans: a scientific statement from the American Heart Association. Hypertension 2019; 73:E35-E66.

4 A\&D. Digital Blood Pressure Monitor Model UA-767 BT: Instruction Manual. http://www.aandd.jp/products/manual/medical/ua767pbtc_fr.pdf

5 OMRON. M3 Digital Automatic Blood Pressure Monitor: Instruction Manual. http://www.omron-healthcare.fr

6 Nerenberg KA, Zarnke KB, Leung AA, Dasgupta K, Butalia S, McBrien K, et al. Hypertension Canada's 2018 Guidelines for Diagnosis, Risk Assessment, Prevention, and Treatment of Hypertension in Adults and Children. Can J Cardiol 2018; 34:506525.

7 James PA, Oparil S, Carter BL, Cushman WC, Dennison-Himmelfarb C, Handler J, et al. 2014 Evidence-Based Guideline for the Management of High Blood Pressure in Adults. JAMA 2014; 311:507.

8 Whelton PK, Carey RM, Aronow WS, Casey DE, Collins KJ, Dennison Himmelfarb C, et 
al. 2017 ACC/AHA/AAPA/ABC/ACPM/AGS/APhA/ASH/ASPC/NMA/PCNA Guideline for the Prevention, Detection, Evaluation, and Management of High Blood Pressure in Adults. Hypertension 2018; 71:1269-1324.

9 O’Brien E, Asmar R, Beilin L, Imai Y, Mallion JM, Mancia G, et al. European Society of Hypertension recommendations for conventional, ambulatory and home blood pressure measurement. J Hypertens 2003; 21:821-848.

10 National Institute for Health and Care Excellence. Hypertension in adults: diagnosis and management (NICE Guideline 136). 2011.

11 Société française d’hypertension artérielle. Recommandations pour la mesure de la pression artérielle. 2018.

12 Williams B, Mancia G, Spiering W, Rosei EA, Azizi M, Burnier M, et al. 2018 ESC/ESH Guidelines for the management of arterial hypertension. The Task Force for the management of arterial hypertension of the European Society of Cardiology and the European Society of Hypertension. J. Hypertens. 2018; 36:1956-2041.

13 O’Brien E, Asmar R, Beilin L, Imai Y, Mancia G, Mengden T, et al. Practice guidelines of the European Society of Hypertension for clinic, ambulatory and self blood pressure measurement. J. Hypertens. 2005; 23:697-701.

14 Liberati A, Altman DG, Tetzlaff J, Mulrow C, Gøtzsche PC, loannidis JPA, et al. The PRISMA Statement for Reporting Systematic Reviews and Meta-Analyses of Studies That Evaluate Health Care Interventions: Explanation and Elaboration. PLoS Med 2009; 6:e1000100.

15 Whiting PF, Rutjes AWS, Westwood ME, Mallett S, Deeks JJ, Reitsma JB, et al. Quadas2: A revised tool for the quality assessment of diagnostic accuracy studies. Ann Intern Med 2011; 155:529-536. 
16 Wołoszyn P, Baumberg I, Baker D. The Reliability of Noninvasive Blood Pressure Measurement Through Layers of Autumn/Winter Clothing: A Prospective Study. Wilderness Environ Med 2019; 30:227-235.

17 Eder MJC, Holzgreve H, Liebl ME, Bogner JR. Der einfluss von bekleidung auf die sphygmomanometrische und oszillometrische blutdruckmessung bei hypertonikern. Dtsch Medizinische Wochenschrift 2008; 133:1288-1292.

18 Ozone S, Sato M, Takayashiki A, Sato T, Matsushita A, Yoshimoto H, et al. Blood pressure measurements over thin and thick sleeves in the frail elderly. Blood Press Monit 2018; 23:9-11.

$19 \mathrm{Ki} \mathrm{JH}, \mathrm{Oh} \mathrm{MK}$, Lee SH. Differences in blood pressure measurements obtained using an automatic oscillometric sphygmomanometer depending on clothes-wearing status. Korean J Fam Med 2013; 34:145-151.

20 Liebl M, Holzgreve H, Schulz M, Crispin A, Bogner J. The effect of clothes on sphygmomanometric and oscillometric blood pressure measurement. Blood Press $2004 ; 13: 279-282$.

21 Ertug N, Cakal T, Ozturk SB, Verim M. The effect of clothes on blood pressure measurement. Pakistan J Med Sci 2017; 33:205-209.

22 Holleman DR, Westman EC, McCrory DC, Simel DL. The effect of sleeved arms on oscillometric blood pressure measurement. J Gen Intern Med 1993; 8:325-326.

23 Kahan E, Yaphe J, Knaani-Levinz H, Weingarten MA. Comparison of blood pressure measurements on the bare arm, below a rolled-up sleeve, or over a sleeve. Fam Pract $2003 ; 20: 730-732$.

24 Thien T, Keltjens EBM, Lenders JWM, Deinum J. Should blood pressure be measured with the cuff on a bare arm? Blood Press Monit 2015; 20:320-324. 
25 Ma G, Sabin N, Dawes M. A comparison of blood pressure measurement over a sleeved arm versus a bare arm. Cmaj 2008; 178:585-589.

26 Pinar R, Ataalkin S, Watson R. The effect of clothes on sphygmomanometric blood pressure measurement in hypertensive patients. J Clin Nurs 2010; 19:1861-1864.

27 Bland JM, Altman DG. Statistical methods for assessing agreement between two methods of clinical measurement. Lancet 1986; 1:307-10.

28 Ahmed I. Measuring the blood pressure: do we really need sleeves rolled up? Pakistan Hear J 2006; 39:38-41.

29 Ozone S, Shaku F, Sato M, Takayashiki A, Tsutsumi M, Maeno T. Comparison of blood pressure measurements on the bare arm, over a sleeve and over a rolled-up sleeve in the elderly. Fam Pract 2016; 33:517-522.

30 Kottner J, Audigé L, Brorson S, Donner A, Gajewski BJ, Hróbjartsson A, et al. Guidelines for Reporting Reliability and Agreement Studies (GRRAS) were proposed. J Clin Epidemiol 2011; 64:96-106.

31 Hoshide S. Clinical implication of visit-to-visit blood pressure variability. Hypertens Res 2018; 41:993-999.

32 White WB, Berson AS, Robbins C, Jamieson MJ, Prisant LM, Roccella E, et al. National standard for measurement of resting and ambulatory blood pressures with automated sphygmomanometers. Hypertens (Dallas, Tex 1979) 1993; 21:504-9.

33 Cohen JF, Korevaar DA, Altman DG, Bruns DE, Gatsonis CA, Hooft L, et al. STARD 2015 guidelines for reporting diagnostic accuracy studies: explanation and elaboration. BMJ Open 2016; 6:e012799. 
Table 1. Methods of BP measurement

\begin{tabular}{|c|c|c|c|c|c|}
\hline Study & Comparison & Type and thickness of sleeve & $\begin{array}{c}\text { Order of } \\
\text { measurement }\end{array}$ & $\begin{array}{l}\text { Measurement } \\
\text { technique (position of } \\
\text { stethoscope) }\end{array}$ & $\begin{array}{l}\text { Measures for } \\
\text { each cuff } \\
\text { placement }\end{array}$ \\
\hline Ahmed 2006 & Bare vs Sleeve & Participant's sleeve: $0.83 \mathrm{~cm}$ (mean) & Unspecified & $\begin{array}{l}\text { Auscultatory mercury } \\
\text { (unspecified) }\end{array}$ & 3 \\
\hline Eder 2008 & Bare vs Sleeve & $\begin{array}{l}\text { Participant's sleeve: usually < } 1 \mathrm{~mm} \text {, } \\
\text { always }<2 \mathrm{~mm} \text {; or standard cotton } \\
\text { sleeve: } 2 \mathrm{~mm} \text { (mean) }\end{array}$ & Randomized & $\begin{array}{l}\text { Oscillometric; } \\
\text { auscultatory aneroid } \\
\text { (unspecified) }\end{array}$ & 3 \\
\hline Ertug 2017 & Sleeve vs Rolled-up sleeve & Participant's sleeve; 1 mm (mean) & $\begin{array}{l}\text { Sleeved then } \\
\text { rolled-up sleeve }\end{array}$ & $\begin{array}{l}\text { Auscultatory mercury } \\
\text { (unspecified) }\end{array}$ & 1 \\
\hline Holleman 1993 & Bare vs Sleeve & $\begin{array}{l}\text { Cotton-polyester shirt; shirt+acrylic } \\
\text { lightweight sweater }\end{array}$ & Simultaneous & Oscillometric & 3 \\
\hline Kahan 2003 & $\begin{array}{l}\text { Bare vs Sleeve; Sleeve vs } \\
\text { Rolled-up sleeve }\end{array}$ & Participant's sleeve: 1.7 mm (mean) & Randomized & Oscillometric & 3 \\
\hline Ki 2013 & $\begin{array}{l}\text { Bare vs Sleeve vs Rolled-up } \\
\text { sleeve }\end{array}$ & $\begin{array}{l}\text { Participant's sleeve: } 84 \%<2 \mathrm{~mm} ; 16 \% \geq \\
2 \mathrm{~mm}\end{array}$ & Randomized & Oscillometric & 3 \\
\hline Liebl 2004 & Bare vs Sleeve & $\begin{array}{l}\text { Participant's sleeve: } 77.1 \%<1 \mathrm{~mm} ; \\
23.9 \% 1-2 \mathrm{~mm}\end{array}$ & Randomized & $\begin{array}{l}\text { Oscillometric; } \\
\text { auscultatory aneroid } \\
\text { (over the sleeve) }\end{array}$ & Unspecified \\
\hline Ma 2008 & Bare vs Sleeve & Participant's sleeve: $4.3 \mathrm{~mm}$ (mean) & $\begin{array}{l}\text { Bare then } \\
\text { [sleeved or bare] }\end{array}$ & Oscillometric & 2 \\
\hline
\end{tabular}




\begin{tabular}{|l|l|l|l|l|l|}
\hline Ozone 2016 & $\begin{array}{l}\text { Bare vs Sleeve vs Rolled-up } \\
\text { sleeve }\end{array}$ & $\begin{array}{l}\text { Participant's sleeve, unless }>1 \mathrm{~mm} \text {, or } \\
\text { standard sleeve: } 1 \mathrm{~mm} \text {-thick wool-nylon } \\
\text { cardigan) }\end{array}$ & Alternative & Oscillometric \\
\hline Ozone 2018 & $\begin{array}{l}\text { Bare vs Sleeve vs Rolled-up } \\
\text { sleeve }\end{array}$ & $\begin{array}{l}\text { Cotton+polyester shirt }(<0.5 \mathrm{~mm}) \pm \\
\text { nylon-wool cardigan }(<1.5 \mathrm{~mm})\end{array}$ & Alternative & Oscillometric & 2 \\
\hline Pinar 2009 & Bare vs Sleeve & Participant's sleeve: $\leq 2 \mathrm{~mm}$ & $\begin{array}{l}\text { Bare then sleeved } \\
\text { then bare }\end{array}$ & $\begin{array}{l}\text { Auscultatory mercury } \\
\text { (unspecified) }\end{array}$ & 2 \\
\hline Thien 2015 & Bare vs Sleeve & $\begin{array}{l}\text { Participant's sleeve or standardized } \\
\text { fleece sleeve, always }<2 \mathrm{~mm}\end{array}$ & Randomized & Oscillometric \\
\hline Woloszyn 2019: & Bare vs Sleeve & $\begin{array}{l}\text { Standardized 2-layer (8 mm) and 3-layer } \\
\text { (17 mm) sleeves of cotton, polar fabric } \\
\text { and down-fitted double-textile }\end{array}$ & Randomized & Oscillometric \\
\hline
\end{tabular}


Table 2. Risk of bias within studies

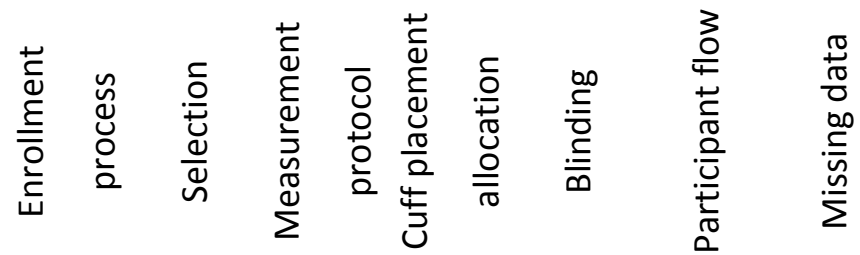

\begin{tabular}{|c|c|c|c|c|c|c|c|}
\hline & & & & & & & \\
\hline Ahmed 2006 & $?$ & (i) & (i) & ? & 2 & 2 & ? \\
\hline Eder 2008 & $?$ & (i) & (i) & (i) & (i) & 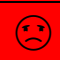 & ? \\
\hline Ertug 2017 & $?$ & (i) & ? & 2 & 2 & (i) & $?$ \\
\hline Holleman 1993 & $?$ & 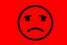 & ? & $\theta$ & $?$ & 2 & ? \\
\hline Kahan 2003 & (i) & $(2)$ & (i) & (i) & $?$ & 2 & ? \\
\hline Ki 2013 & $?$ & (i) & (i) & (i) & $?$ & 2 & ? \\
\hline Liebl 2004 & $?$ & (;) & (i) & (i) & (i) & $\approx$ & ? \\
\hline Ma 2008 & (i) & (i) & ? & (i) & $\approx$ & (i) & ? \\
\hline Ozone 2016 & ? & (i) & (i) & 2 & $?$ & 2 & $?$ \\
\hline Ozone 2018 & $?$ & (i) & (i) & $\theta$ & $?$ & 2 & ? \\
\hline Pinar 2009 & $?$ & (i) & (i) & 2 & (i) & 2 & $?$ \\
\hline Thien 2015 & $?$ & 2 & (i) & (i) & ? & $\theta$ & ? \\
\hline Woloszyn 2019 & $?$ & (;) & $?$ & (i) & $\approx$ & 2 & ? \\
\hline
\end{tabular}


Table 3. Results of individual studies

\begin{tabular}{|c|c|c|c|c|c|c|c|}
\hline & \multirow{2}{*}{ Comparison } & \multirow{2}{*}{ Method } & \multicolumn{2}{|c|}{$\begin{array}{c}\text { Mean BP on bare arm } \\
(\mathrm{SD})\end{array}$} & \multirow{2}{*}{$\begin{array}{c}\text { Sleeve } \\
\text { thickness }\end{array}$} & \multicolumn{2}{|c|}{$\begin{array}{c}\text { Mean sleeve - bare } \\
\text { BP difference (SD or } \mathrm{Cl})\end{array}$} \\
\hline & & & $\begin{array}{c}\text { SBP } \\
(\mathrm{mmHg})\end{array}$ & $\begin{array}{c}\text { DBP } \\
(\mathrm{mmHg})\end{array}$ & & SBP (mmHg) & DBP (mmHg) \\
\hline Ahmed 2006 & Sleeve vs bare & Auscultatory & $112.9(15.1)$ & 74.1 (9.9) & Thin & $0.94(0.33 ; 1.54)$ & $0.58(0.04 ; 1.10)$ \\
\hline Eder 2008 & Standard sleeve vs bare & Oscillometric & Unspecified & Unspecified & Thick & $0.84(-0.35 ; 2.03)$ & $2.03(1.38 ; 2.68)$ \\
\hline Eder 2008 & Own sleeve vs bare & Oscillometric & Unspecified & Unspecified & Thin & $-0.9(-1.82 ;-0.11)$ & $1.23(0.53 ; 1.93)$ \\
\hline Eder 2008 & Aneroid standard sleeve vs bare & Auscultatory & Unspecified & Unspecified & Thick & $0.94(0.37-1.73)$ & $1.78(1.18 ; 2.37)$ \\
\hline Eder 2008 & Aneroid participant's sleeve vs bare & Auscultatory & Unspecified & Unspecified & Thin & $0.15(-0.57 ; 0.87)$ & $0.68(0.07 ; 1.28)$ \\
\hline Ertug 2017 & Rolled-up sleeve vs sleeve & Auscultatory & Unspecified & Unspecified & Thin & Unspecified & Unspecified \\
\hline Holleman 1993 & Thin sleeve vs bare & Oscillometric & $130(27.7)$ & $75(13.7)$ & Thin & $-1.7(-5.3 ; 1.9)$ & $-2.2(-4.4 ; 0.1)$ \\
\hline Holleman 1993 & Thick sleeve vs bare & Oscillometric & $131(27.7)$ & $76(13.7)$ & Thick & $0.5(-3.0 ; 4.1)$ & $-0.8(-3.1 ; 1.4)$ \\
\hline Kahan 2003 & Rolled-up sleeve vs bare & Oscillometric & $123.6(19)$ & $73.2(10)$ & Thin & $-0.54(7.4)$ & $0.56(4.6)$ \\
\hline Kahan 2003 & Sleeve vs bare & Oscillometric & $123.6(19)$ & $73.2(10)$ & Thin & $0.02(7.6)$ & $1.27(5.6)$ \\
\hline Ki 2013 & Sleeve vs bare & Oscillometric & $128.3(10.7)$ & $80.6(5.9)$ & Unclear & $0.20(-1.56 ; 1.96)$ & $0.10(-0.89 ; 1.09)$ \\
\hline Ki 2013 & Rolled-up sleeve vs bare & Oscillometric & $128.3(10.7)$ & $80.6(5.9)$ & Unclear & $0.0(-1.77 ; 1.77)$ & $0.10(-0.89 ; 1.09)$ \\
\hline Liebl 2004 & Sleeve vs bare & Oscillometric & Unspecified & Unspecified & Thin & $1.1(-0.2 ; 2.4)$ & $0.5(-0.4 ; 1.4)$ \\
\hline Liebl 2004 & Aneroid sleeve vs bare & Auscultatory & Unspecified & Unspecified & Thin & $1.0(-0.2 ; 2.1)$ & $0.8(0.1 ; 1.7)$ \\
\hline Ma 2008 & Sleeve vs bare & Oscillometric & $138.5(19.6)$ & $78(10.2)$ & Thick & $0.76(-1.13 ; 2.65)$ & $-0.31(-1.48 ; 0.86)$ \\
\hline Ozone 2016 & Sleeve vs bare & Oscillometric & $128.9(19.1)$ & $67.4(10.8)$ & Thin & $3.76(9.96)^{*}$ & $5.0(6.5)^{*}$ \\
\hline Ozone 2016 & Rolled-up sleeve vs bare & Oscillometric & $128.9(19.1)$ & $67.4(10.8)$ & Thin & $4.39(11.89)^{*}$ & $6.8(7.0)^{*}$ \\
\hline Ozone 2018 & Shirt sleeve vs bare & Oscillometric & $128.8(20)$ & $69.3(13.2)$ & Thin & $2.2(11.3)^{*}$ & $4.6(9.0)^{*}$ \\
\hline
\end{tabular}




\begin{tabular}{|c|c|c|c|c|c|c|c|}
\hline Ozone 2018 & Cardigan sleeve vs bare & Oscillometric & $128.8(20)$ & $69.3(13.2)$ & Thick & $8.1(14.2)^{*}$ & $9.6(10.6)^{*}$ \\
\hline Ozone 2018 & Rolled-up sleeve vs bare & Oscillometric & $128.8(20)$ & $69.3(13.2)$ & Thick & $7.6(16)^{*}$ & $11.4(10.8)^{*}$ \\
\hline Pinar 2009 & Sleeve vs bare & Auscultatory & $137.3(19.1)$ & 80.5 (11.9) & Thin & $-0.10(-2.69 ; 1.89)$ & $-0.2(-1.64 ; 1.24)$ \\
\hline Thien 2015 & Standard sleeve vs bare & Oscillometric & $132.8(15)$ & $78.3(10.4)$ & Thin & $0.4(5.9)$ & $-0.2(3.5)$ \\
\hline Thien 2015 & Own sleeve vs bare & Oscillometric & $132.8(15)$ & $78.3(10.4)$ & Thin & $0.5(6.0)$ & $0.0(4.0)$ \\
\hline Woloszyn 2019 v & Volunteers 2-layer sleeve vs bare & Oscillometric & $130(14)$ & $80(8)$ & Thick & $-0.3(6.6)^{*}$ & $1.2(6.4)^{*}$ \\
\hline Woloszyn 2019 p & Patients 2-layer sleeve vs bare & Oscillometric & $139.5(34.4)$ & $81.9(15.3)$ & Thick & $0.0(6.5)^{*}$ & $1.7(5.6)^{*}$ \\
\hline Woloszyn 2019 v & Volunteers 3-layer sleeve vs bare & Oscillometric & $130.3(14.1)$ & $79.5(8.2)$ & Thick & $-1.8(8.0)^{*}$ & $1.3(6.7)^{*}$ \\
\hline Woloszyn 2019 p & Patients 3-layer sleeve vs bare & Oscillometric & $139.5(34.4)$ & $81.9(15.3)$ & Thick & $-2.9(23.4)^{*}$ & $2.6(5.9)^{*}$ \\
\hline
\end{tabular}

* data kindly provided by the first authors of the studies 
Study

Ahmed 2006

Eder 2008

Holleman 1993

Kahan 2003

Ki 2013

Liebl 2004

Ma 2008

Ozone 2016

Ozone 2018

Pinar 2009

Thien 2015

Woloszyn 2019 p

Woloszyn 2019 hv

Number of subjects

with $95 \% \mathrm{Cl}$

200

203

36

201

141

201

180+196

186

147

258

133

50

101

Overall $(\mathrm{I}$-squared $=71 \%, \mathrm{p}<0.001$ )

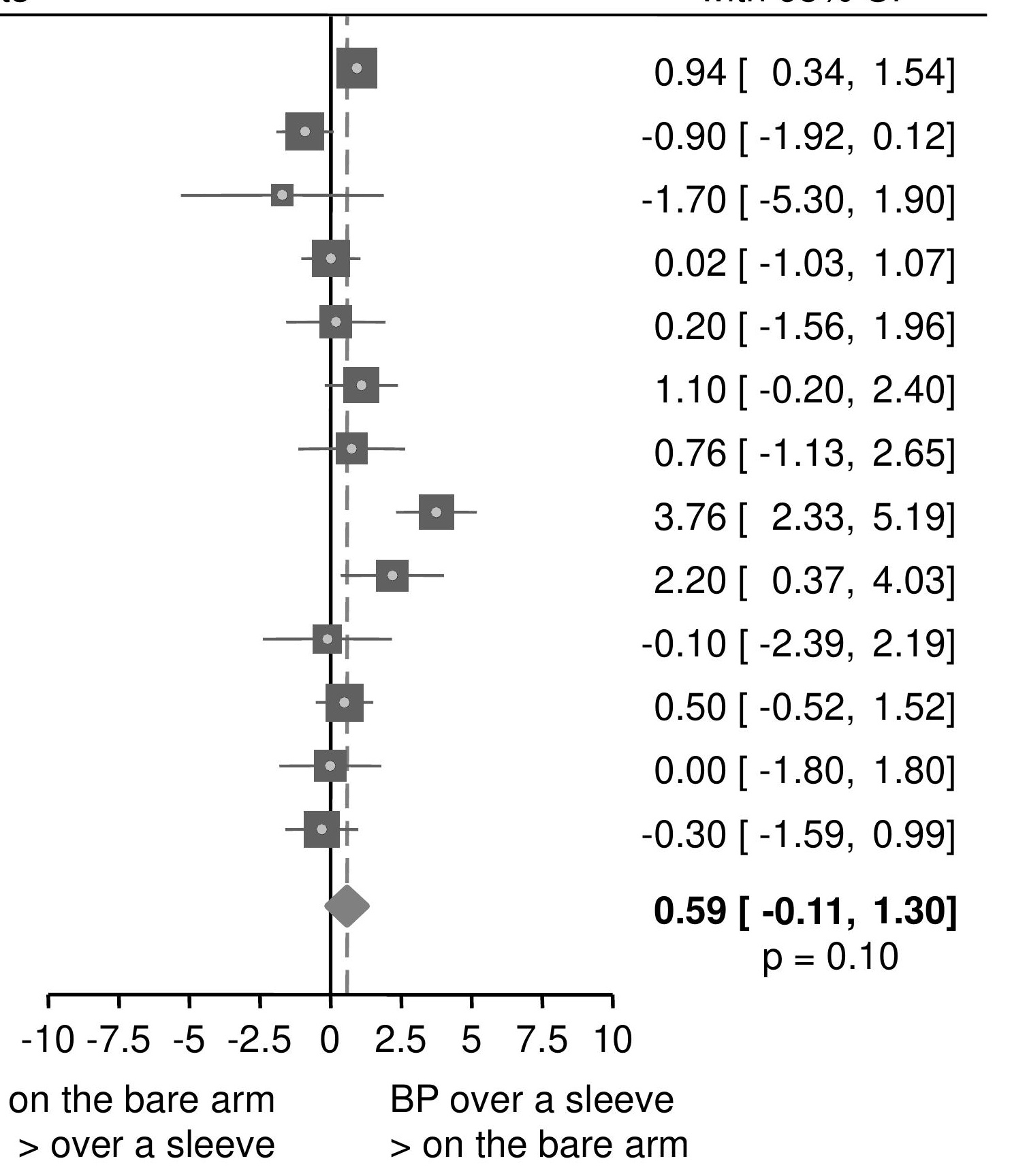

Random-effects REML model 

with $95 \% \mathrm{Cl}$

Ahmed 2006

Eder 2008

Holleman 1993

Kahan 2003

Ki 2013

Liebl 2004

Ma 2008

Ozone 2016

Ozone 2018

Pinar 2009

Thien 2015

Woloszyn 2019 p

Woloszyn 2019 hv

Overall $($ I-squared $=91 \%, p<0.001)$

200

203

36

201

141

201

180+196

186

147

258

133

50

101

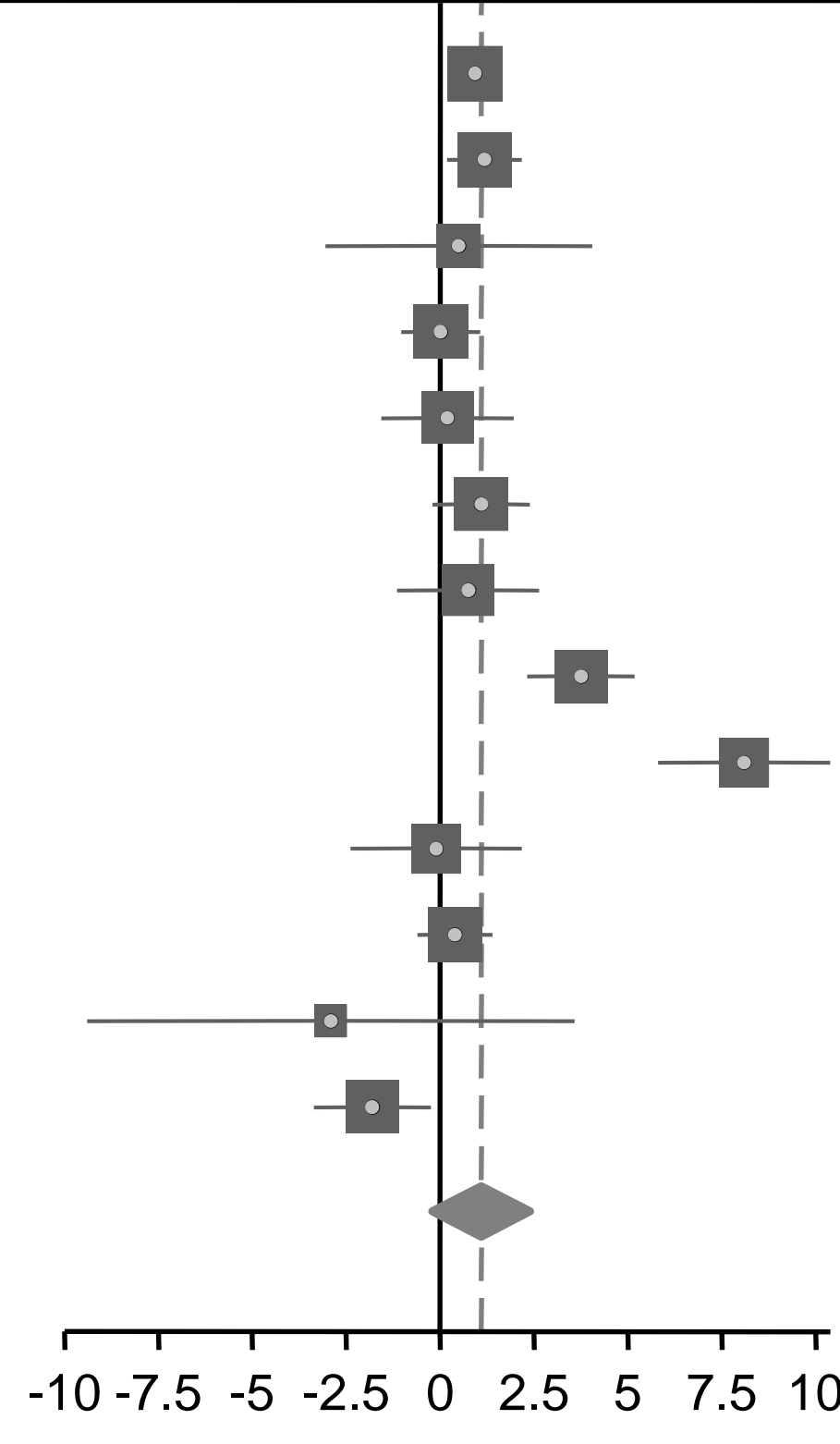

0.94 [ 0.34, 1.54]

1.19 [ 0.19, 2.19]

$0.50[-3.05,4.05]$

$0.02[-1.03,1.07]$

$0.20[-1.56,1.96]$

$1.10[-0.20,2.40]$

$0.76[-1.13,2.65]$

$3.76[2.33,5.19]$

8.10 [ 5.80, 10.40]

$-0.10[-2.39,2.19]$

$0.40[-0.60,1.40]$

$-2.90[-9.39,3.59]$

$-1.80[-3.36,-0.24]$

$1.10[-0.21,2.40]$ $p=0.10$

Random-effects REML model

BP on the bare arm

> over a sleeve
BP over a sleeve $>$ on the bare arm 